\title{
Arterial stiffness in young women with Turner syndrome using cardio-ankle vascular index
}

\author{
You Jung Heo, MD', \\ Hae Woon Jung, $\mathrm{MD}^{2}$, \\ Young Ah Lee, MD, $\mathrm{PhD}^{1}$, \\ Choong Ho Shin, MD, PhD', \\ Sei Won Yang, MD, PhD'
}

${ }^{1}$ Department of Pediatrics, Seoul National University Children's Hospital, Seoul National University College of Medicine, Seoul, Korea

${ }^{2}$ Department of Pediatrics, Kyung Hee University Medical Center, Seoul, Korea

Received: 13 September, 2018

Revised: 1 November, 2018

Accepted: 12 November, 2018

Address for correspondence:

Young Ah Lee, MD, PhD

Department of Pediatrics, Seoul

National University Children's Hospital, 101 Daehak-ro, Jongno-gu,

Seoul 03080, Korea

Tel: +82-2-2072-2308

Fax: +82-2-743-3455

E-mail:nina337@snu.ac.kr

https://orcid.org/0000-0001-91791247

Address for co-correspondence: Hae Woon Jung, MD

Department of Pediatrics, Kyung Hee University Medical Center, 23 Kyung Hee Dae-ro, Dongdaemungu, Seoul 02447, Korea

Tel: +82-2-958-8143

Fax: +82-2-958-8304

E-mail:woonieya@gmail.com

https://orcid.org/0000-0003-04944626
Purpose: Patients with Turner syndrome (TS) have increased risk of morbidities and mortality related to cardiovascular complications. Cardio-ankle vascular index $(\mathrm{CAVI})$ is a novel method of evaluating arterial stiffness independent of changes in blood pressure. We compared arterial stiffness using CAVI between TS patients and healthy control subjects.

Methods: Nineteen young women with TS (mean, 26.8 years; range, 20.0-35.1 years) and 23 healthy women matched for age and body mass index (BMI) were recruited for CAVI measurements at Seoul National University Hospital between 2010 and 2013. Anthropometric parameters, fasting blood testing and measurements of CAVI were compared between the 2 groups.

Results: TS patients were significantly shorter (mean: $150.1 \mathrm{~cm}$ vs. $160.7 \mathrm{~cm}$, $P<0.001$ ) and had lower body weight (mean: $47.0 \mathrm{~kg}$ vs. $55.5 \mathrm{~kg}, P=0.014$ ) than healthy controls, without difference in BMI. CAVI (6.5 \pm 0.6 vs. $6.1 \pm 0.6, P=0.039)$ was significantly higher in TS patients compared to healthy controls. Age was positively associated with CAVI $(r=0.403, P=0.008)$ in univariate analysis. After adjusting for age, TS was associated with CAVI $(P=0.006)$.

Conclusion: Young women with TS showed increased arterial stiffness measured by CAVI compared to healthy women after adjusting for age, suggesting inherent vasculopathy in TS patients.

Keywords: Turner syndrome, Cardiovascular abnormalities, Vascular stiffness

\section{Introduction}

Turner syndrome (TS) is a sex chromosomal disorder caused by monosomy or structural abnormality of one of the X chromosomes and affects 1 in 3,000 live-born females. Compared to the general population, women with TS have a 3-fold higher mortality risk mostly related to cardiovascular complications including aortic aneurysm and/or valve disorder. ${ }^{1,2)}$ Bicuspid aortic valve, coarctation of the aorta (CoA), and hypertension (HTN) are well-known risk factors for aortic dilatation which can lead to serious complications, such as rupture or dissection of the aorta. ${ }^{3,4)}$

TS patients should receive echocardiography for screening congenital heart disease at diagnosis and after reaching adulthood, and monitoring of cardiovascular and metabolic risk factors is imperative during follow-up. ${ }^{5}$ Considering vascular causes of mortality in TS patients, measurement of arterial stiffness is necessary to monitor vascular function. ${ }^{6)}$ Pulse wave velocity (PWV) is the commonly used standard measure of central arterial stiffness, ${ }^{7,8)}$ however PWV can be affected by blood pressure (BP). Hence, the cardio-ankle vascular index (CAVI), which reflects the stiffness of the aorta as well as the femoral and tibial arteries, may be a useful indicator independent of $\mathrm{BP}^{9,10)} \mathrm{CAVI}$ measurement is helpful to quantitatively assess the extent of atherosclerosis in major arteries from an aortic valve to ankle in patients with cardiovascular diseases, as well as for screening in patients at a subclinical stage. 
Several clinical studies using CAVI have been conducted in diabetes mellitus and chronic renal disease patients with good reproducibility. ${ }^{911,12)}$ While clinical studies investigating arterial stiffness using PWV in TS patients have been reported, ${ }^{6,13)}$ arterial stiffness using CAVI has not been studied in TS patients.

In the present study, we compared CAVI between TS patients and healthy control subjects. We also investigated whether arterial stiffness was reduced in TS patients compared to controls after adjusting for covariates.

\section{Materials and methods}

\section{Subjects}

Young adult women with TS confirmed by a karyotype were recruited for measurement of arterial stiffness at Seoul National University Children's Hospital between August 2010 and June 2013. After excluding patients with comorbid type 2 diabetes mellitus $(n=6)$, HTN requiring medication $(n=1)$, aortic disorders such as valve stenosis and $\operatorname{CoA}(n=5)$, and those who did not want to undergo CAVI $(n=11)$, a total of 19 patients were finally included in this study. A total of 23 healthy women matched for age and body mass index (BMI) were enrolled for comparison with TS patients. Clinical characteristics including karyotype, congenital heart anomaly, and medication records were retrospectively reviewed.

\section{Anthropometric and BP measurements}

Anthropometric parameters were assessed including height, weight, and waist circumference (WC) at the level of the umbilicus. BMI was calculated as weight $(\mathrm{kg})$ divided by height squared $\left(\mathrm{m}^{2}\right)$. Body surface area (BSA) was calculated as the square root of the product of weight $(\mathrm{kg})$ and height $(\mathrm{cm})$ divided by 3,600. ${ }^{14)}$ Brachial BP was measured in the patient's left arm in a sitting position using the Colin BP-S510 patient monitor (DRE, Louisville, KU, USA) after a 10-minute rest. Two readings were taken and mean systolic and diastolic BP were calculated.

\section{Measurements of metabolic parameters}

Blood samples were obtained after 12 hours of fasting to measure fasting glucose, insulin, total cholesterol, triglyceride (TG), high-density lipoprotein (HDL) cholesterol, low-density lipoprotein (LDL) cholesterol, aspartate transaminase, and alanine transferase. The homeostasis model insulin resistance index (HOMA-IR) was calculated as the product of fasting insulin (mIU/L) and glucose (mg/dL) divided by $405 .{ }^{15)}$ Central obesity was defined according to the definition for Asian populations (WC $\geq 80 \mathrm{~cm}$ in women). Impaired fasting glucose (IFG) was diagnosed as fasting blood glucose levels $\geq 100 \mathrm{mg} /$ $\mathrm{dL}$, according to the definition by the International Diabetes Federation. ${ }^{16)}$ Dyslipidemia was diagnosed when TG levels were above $150 \mathrm{mg} / \mathrm{dL}$ and/or HDL cholesterol levels were below 50 $\mathrm{mg} / \mathrm{dL}$ as recommended by the National Cholesterol Education Program Adult Treatment Panel III. ${ }^{17)}$

\section{Measurements of arterial stiffness}

CAVI was measured using the vascular screening system VaSera VS-1000 (Fukuda Denshi, Tokyo, Japan). Measurements were performed as described in previous studies. ${ }^{9,18)}$ The subject was placed in a supine position after resting for at least 10 minutes. Cuffs were wrapped around both the upper arms and ankles, and electrocardiographic electrodes were placed on both wrists. The phonocardiogram was obtained using a microphone placed at the sternal angle. PWV from the heart to the ankle was obtained by measuring the vascular length and the time of PWV propagation. The value of CAVI was calculated from PWV by the software system according to the following formula: $C A V I=a\left[(2 p / \Delta P) \times \ln \left(P_{s} / P_{d}\right) P W V^{2}\right]+b$ where $P_{s}$ and $\mathrm{Pd}$ are systolic and diastolic BP values, respectively. PWV is the pulse wave velocity between heart and ankle, $\Delta \mathrm{P}$ is $\mathrm{P}_{\mathrm{s}}-\mathrm{P}_{\mathrm{d}}, p$ is blood density, and a and $\mathrm{b}$ are constants. The values of right and left CAVI were calculated, and the average of the right and left CAVIs was used as the value of CAVI for analysis. The value of CAVI determines the degree of arteriosclerosis including its segments from the proximal ascending aorta to the femoral and tibial arteries, and a high CAVI value suggests higher arterial stiffness. ${ }^{18)}$

\section{Statistical analysis}

Statistical analyses were performed using IBM SPSS Statistics ver. 22.0 (IBM Co., Armonk, NY, USA). Continuous variables were tested for normal distribution. Student $t$-test was used to compare the means of continuous variables for normally distributed data and expressed as mean \pm standard deviations (SD). Mann-Whitney $U$-test was used to compare the nonnormal distributed data presented as median (interquartile range, IQR). The Fisher exact test were used to compare categorical variables between the 2 groups. Univariate and multivariate linear regression analyses were performed to identify independent factors affecting the results of CAVI. Variables found to be statistically significant $(P<0.1)$ in the univariate analysis were included in the multivariate-adjusted model. Statistical significance was defined as $P<0.05$.

\section{Results}

\section{Baseline characteristics of women with Turner syndrome}

Karyotypes of TS patients included 45, X monosomy ( $\mathrm{n}=6$, $31.6 \%), 45, X / 46, X+\operatorname{mar}(Y)(n=2), 45, X / 46 X i(X q)(n=6)$, $45, X / 46, X X(n=4)$, and 46,Xi $(X q) / 47, X i(X q) i(X q)(n=1)$. Two of the patients had renal anomalies (1 horseshoe kidney and 1 
renal cyst). Eight of the patients were diagnosed with euthyroid Hashimoto's thyroiditis. All patients discontinued growth hormone therapy after reaching final adult height and received cyclic estrogen-progestogen hormone therapy for a mean duration of 10.9 years $(\mathrm{SD}, 5.4)$.

\section{Comparisons of clinical characteristics between TS patients and controls}

Comparisons of clinical characteristics between TS patients and controls are shown in Table 1. The mean age and BMI of TS patients and healthy controls were matched. The mean age for TS patients was 26.8 years (SD, 4.3; range, 20.0-35.1 years) and for controls was 28.2 years (SD, 5.2; range, 18.8-34.7 years). The mean BMI for TS patients was $21.3 \mathrm{~kg} / \mathrm{m}^{2}$ (IQR, 19.8-24.4 $\mathrm{kg} / \mathrm{m}^{2}$ ) and for controls was $21.3 \mathrm{~kg} / \mathrm{m}^{2}$ (IQR, 20.2-24.7 kg/ $\mathrm{m}^{2}$ ). TS Patients were significantly shorter (mean: $150.1 \mathrm{~cm}$ vs. $160.7 \mathrm{~cm}, P<0.001$ ) and had lower body weight (mean: $47.0 \mathrm{~kg}$ vs. $55.5 \mathrm{~kg}, P=0.014)$ and lower BSA $\left(1.4 \mathrm{~m}^{2}\right.$ vs. $\left.1.6 \mathrm{~m}^{2}, P<0.001\right)$ than healthy controls. WC was significantly greater in TS patients than in controls $(90.2 \mathrm{~cm}$ vs. $71.0 \mathrm{~cm}, P<0.001)$ without difference in the proportion of subjects with central obesity (11.1\% vs. $11.8 \%)$.

In TS patients, fasting blood glucose and insulin levels were
$81.6 \mathrm{mg} / \mathrm{dL}(\mathrm{SD}, 6.5)$ and $6.9 \mathrm{mU} / \mathrm{L}(\mathrm{SD}, 2.7)$, respectively, and HOMA-IR was 1.4 (SD, 0.6). None were diagnosed with IFG. Fasting lipid levels did not differ between the two groups Three TS patients (2 patients with TG levels above $150 \mathrm{mmol} /$ $\mathrm{L}$ and 1 patient with HDL cholesterol below $50 \mathrm{mmol} / \mathrm{L}$ ) and one control subject (HDL cholesterol below $50 \mathrm{mmol} / \mathrm{L}$ ) were diagnosed with dyslipidemia. The levels of liver enzymes did not differ between the 2 groups. TS patients had significantly higher systolic BP than healthy controls $(123.2 \pm 12.3 \mathrm{mmHg}$ vs. $111.1 \pm 7.9 \mathrm{mmHg}, P=0.001)$ without differences in diastolic BP.

\section{Comparison of arterial stiffness between TS patients and controls}

Table 2 shows measurements of vascular parameters including arterial stiffness. CAVI was significantly higher in TS patients compared to healthy controls $(6.5 \pm 0.6$ vs. $6.1 \pm 0.6, P=0.039)$ (Fig. 1), suggesting greater arterial stiffness in TS patients. No significant differences were found in aortic PWV between the two groups, even after adjusting for BSA and height.

\section{Risk factors for arterial stiffness}

Univariate and multivariate analyses were performed to

Table 1. Comparison of clinical characteristics between Turner syndrome patients and controls

\begin{tabular}{|c|c|c|c|}
\hline Variable & Turner syndrome patients ( $n=19)$ & Controls $(n=23)$ & $P$-value \\
\hline Age (yr) & $26.8 \pm 4.3$ & $28.2 \pm 5.2$ & 0.343 \\
\hline Height (cm) & $150.1 \pm 6.0$ & $160.7 \pm 5.1$ & $<0.001$ \\
\hline Weight (kg) & $47.0(42.0-54.7)$ & $55.5(50.0-64.0)$ & 0.014 \\
\hline Body mass index $\left(\mathrm{kg} / \mathrm{m}^{2}\right)$ & $21.3(19.8-24.4)$ & $21.3(20.2-24.7)$ & 0.970 \\
\hline Body surface area $\left(\mathrm{m}^{2}\right)$ & $1.4(1.3-1.5)$ & $1.6(1.5-1.8)$ & $<0.001$ \\
\hline Waist circumference (cm) & $90.2(85.5-92.4)$ & $71.0(68.5-80.0)$ & $<0.001$ \\
\hline Central obesity & 2/18 (11.1) & 2/17 (11.8) & 1.000 \\
\hline Cardiac abnormality $^{*}$ & $4 / 19(21.1)$ & N/A & \\
\hline Renal anomaly ${ }^{\dagger}$ & $2 / 19(10.5)$ & $\mathrm{N} / \mathrm{A}$ & \\
\hline Thyroiditis & $8 / 19(42.1)$ & N/A & \\
\hline Fasting glucose level (mg/dL) & $81.6 \pm 6.5$ & N/A & \\
\hline Impaired fasting glucose (n) & 0 & N/A & \\
\hline Fasting insulin level (mU/L) & $6.8 \pm 2.7$ & N/A & \\
\hline HOMA-IR & $1.4 \pm 0.6$ & N/A & \\
\hline Total cholesterol (mmol/L) & $179.1 \pm 25.4$ & $179.8 \pm 22.9$ & 0.922 \\
\hline Triglycerides (mmol/L) & $72.0(62.0-100.0)$ & $71.0(68.5-80.0)$ & 0.524 \\
\hline Triglycerides $\geq 150 \mathrm{mmol} / \mathrm{L}$ & $2 / 19(10.5)$ & 0 & 0.219 \\
\hline LDL cholesterol (mmol/L) & $105.3 \pm 20.9$ & $97.0 \pm 17.7$ & 0.176 \\
\hline HDL cholesterol (mmol/L) & $60.0(54.0-70.0)$ & $62.0(54.0-73.0)$ & 0.957 \\
\hline HDL cholesterol < $50 \mathrm{mmol} / \mathrm{L}$ & $1 / 19(5.3)$ & $1 / 21(4.8)$ & 1.000 \\
\hline Aspartate transaminase (U/L) & $17.0(14.0-23.0)$ & $18(15.0-21.0)$ & 0.654 \\
\hline Alanine transminase (U/L) & $14.0(9.0-21.0)$ & $14(12.0-18.0)$ & 0.495 \\
\hline Systolic blood pressure (mmHg) & $123.2 \pm 12.3$ & $111.1 \pm 7.9$ & 0.001 \\
\hline Diastolic blood pressure (mmHg) & $74(64.0-75.0)$ & $69(67.0-73.5)$ & 0.164 \\
\hline
\end{tabular}


investigate risk factors associated with CAVI. Age ( $r=0.403$, $P=0.008$ ) and TS syndrome (vs. healthy control subjects, $r=0.319, P=0.039$ ) were positively associated with CAVI in univariate analysis. After adjusting for age, the presence of TS was associated with CAVI $(P=0.006)$ (Table 3$)$. These results suggest that TS is an independent risk factor for increased arterial stiffness.

\section{Discussion}

We compared arterial stiffness using CAVI between TS patients and healthy controls. When we included only TS patients without aortic disease, diabetes or HTN, and compared them to age- and BMI-matched healthy controls, TS patients showed significantly higher CAVI than healthy control subjects. After adjusting for age, TS was an independent risk factor for increased arterial stiffness.

In the present study, arterial stiffness measured by CAVI was increased in TS patients compared to control subjects matched for age and BMI. The stiffness of the arterial wall is highly relevant to cardiovascular disease. Arterial wall stiffness directly impacts the ability of the arteries to accommodate the blood ejected by the ventricles during each ejection and promotes increased target organ damage through excessive penetration of pulsatility into peripheral target organs. ${ }^{7)}$ Since TS patients in adulthood are at high risk for cardiovascular disease, a major cause of morbidity and mortality in TS, ${ }^{1)}$ many studies have been conducted to investigate the vascular nature of TS patients. Many studies have reported increased stiffness and decreased distensibility of the aorta, consistent with our results. ${ }^{6,19,20)}$

Table 2. Comparison of vascular parameters between Turner syndrome patients and controls

\begin{tabular}{lccc}
\hline Variable & $\begin{array}{c}\text { Turner syndrome } \\
\text { patients }(n=19)\end{array}$ & $\begin{array}{c}\text { Controls } \\
(n=23)\end{array}$ & P-value \\
\hline Aortic PWV (m/sec) & $5.8 \pm 1.3$ & $6.0 \pm 1.6$ & 0.732 \\
Aortic PWV/body surface area & $4.1 \pm 1.0$ & $3.7 \pm 1.1$ & 0.246 \\
Aortic PWV/height & $0.04 \pm 0.01$ & $0.04 \pm 0.01$ & 0.558 \\
CAVI & $6.5 \pm 0.6$ & $6.1 \pm 0.6$ & 0.039 \\
\hline
\end{tabular}

Values are presented as mean \pm standard deviation

PWV, pulse wave velocity; CAVI, cardio-ankle vascular index.
When measuring arterial stiffness between the 2 groups with different BP results, CAVI is expected to be superior to PWV. The parameters of CAVI were significantly associated with age, but not BP, in this study, supporting CAVI as the superior BP-independent indicator of arterial stiffness. ${ }^{9)}$ In this study, the systolic BP of TS patients was significantly higher than in controls. Although aortic PWV is the gold standard for the measurement of arterial stiffness, aortic PWV needs to be corrected by BP and special technical skill. ${ }^{7)}$ When carotidfemoral PWV was performed by pediatric cardiologists in adolescents with TS, aortic strain and aortic distensibility were significantly lower in TS adolescents than in controls. ${ }^{20)}$ When we compared adults with TS and healthy women using CAVI as a BP-independent indicator, the difference in CAVI was significant.

Women with TS have a higher risk for obesity, metabolic syndrome and type 2 diabetes. $^{21)}$ Aging, high BMI, high BP, high fasting glucose, and dyslipidemia have been reported to

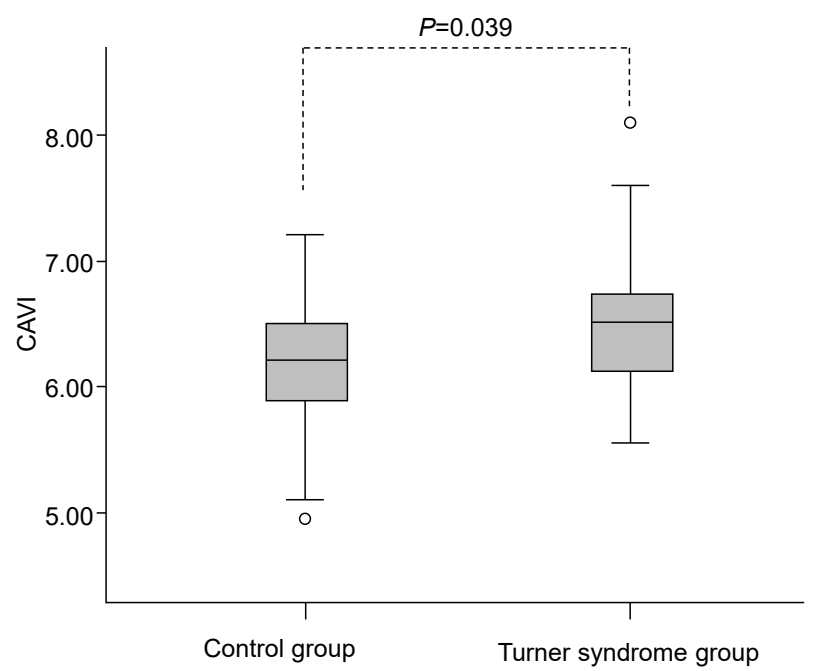

Fig. 1. Comparison of CAVI between women with Turner syndrome and healthy control subjects. CAVI was significantly higher in women with Turner syndrome than in healthy control subjects. $(6.5 \pm 0.6$ vs. $6.1 \pm 0.6, P=0.039)$. CAVI, cardio-ankle vascular index.

Table 3. Risk factors for CAVI among all participants

\begin{tabular}{|c|c|c|c|c|}
\hline \multirow{2}{*}{ Variable } & \multicolumn{2}{|c|}{ Univariate } & \multicolumn{2}{|c|}{ Multivariate } \\
\hline & Coefficient (95\% Cl) & $P$-value & Coefficient $(95 \% \mathrm{Cl})$ & $P$-value \\
\hline Turner syndrome patients (vs. healthy controls) & $0.319(0.021-0.780)$ & 0.039 & $0.388(0.146-0.828)$ & 0.006 \\
\hline Age & $0.403(0.015-0.091)$ & 0.008 & $0.461(0.025-0.096)$ & 0.001 \\
\hline Body mass index & $-0.083(-0.080$ to 0.047$)$ & 0.603 & & \\
\hline Waist circumference & $0.127(-0.014$ to 0.029$)$ & 0.468 & & \\
\hline Triglycerides & $0.181(-0.002$ to 0.009$)$ & 0.264 & & \\
\hline HDL cholesterol & $0.061(-0.014$ to 0.020$)$ & 0.710 & & \\
\hline LDL cholesterol & $0.229(-0.003$ to 0.017$)$ & 0.155 & & \\
\hline Systolic blood pressure & $0.010(-0.017$ to 0.018$)$ & 0.948 & & \\
\hline Diastolic blood pressure & $0.057(-0.015$ to 0.021$)$ & 0.720 & & \\
\hline
\end{tabular}

$\mathrm{CAVI}$, cardio-ankle vascular index; $\mathrm{Cl}$, confidence interval; $\mathrm{HDL}$, high-density lipoprotein; $\mathrm{LDL}$, low-density lipoprotein. 
be associated with increased arterial stiffness and aggravated cardiovascular disorders. ${ }^{22,23)}$ Hence, we recruited age- and BMI-matched control subjects and selected TS patients without diabetes, HTN requiring medication, and aortic diseases. We also adjusted for possible covariates affecting arterial stiffness including age, BMI, BP, WC, and lipid profiles. As a result, TS women showed significantly higher CAVI than matched controls, after adjusting for covariates, supporting that TS patients may have an inherent vascular abnormality of the arterial wall with impaired endothelial function. ${ }^{24)}$ In a study of PWV, augmentation index, and carotid intima media thickness in young TS patients, results showed that minimal structural differences with significant functional differences were possible in young children with TS compared to healthy children matched for age and BMI. ${ }^{13)}$ Furthermore, not only functional but also morphological vascular abnormalities were detected in a study of women with TS, implicating vasculopathy in the origin of cardiovascular complications such as aortic rupture or dissection in adult TS patients. ${ }^{23)}$ Vasculopathy of ruptured aortic walls in TS patients have shown constitutional tissue dysplasia with cystic medial necrosis, similar to patients with Marfan syndrome. ${ }^{25)}$ Therefore, assessment of vascular function and structure followed by periodic monitoring of risk factors is warranted to detect early vasculopathy and prevent cardiovascular complications in TS patients.

Our study has several limitations. First, the number of subjects was relatively small. Second, this study was limited by its crosssectional design. Further longitudinal studies are warranted to evaluate whether arterial stiffness may induce structural changes in TS patients. Third, other factors affecting arterial stiffness such as diet, physical activity, and HOMA-IR (examined only in TS patients) could not be adjusted for due to the lack of information. However, our study is strengthened by being the first investigation of arterial stiffness between TS patients and healthy women matched for age and BMI using CAVI as a BPindependent indicator with adjustment for possible covariates.

In conclusion, young women with TS showed increased CAVI measurements as evidence of increased arterial stiffness compared to age- and BMI-matched healthy women, after adjusting for age, suggesting inherent vasculopathy in TS patients. The beneficial effect of periodic monitoring of vascular function and its risk factors on reduction of cardiovascular complications in adulthood needs to be further investigated.

\section{Ethical statement}

This study complies with the Declaration of Helsinki and was approved by the Institutional Review Board of Seoul National University Hospital (IRB No. H-1306-107-500). Written informed consent was obtained from all participants.

\section{Conflict of interest}

No potential conflict of interest relevant to this article was reported.

\section{Acknowledgments}

This work was supported by the Seoul National University Hospital Research Fund (grant number: 04-2014-3080).

\section{References}

1. Schoemaker MJ, Swerdlow AJ, Higgins CD, Wright AF, Jacobs PA; United Kingdom Clinical Cytogenetics Group. Mortality in women with turner syndrome in Great Britain: a national cohort study. J Clin Endocrinol Metab 2008;93:4735-42.

2. Ostberg JE, Conway GS. Adulthood in women with Turner syndrome. Horm Res 2003;59:211-21.

3. Elsheikh M, Casadei B, Conway GS, Wass JA. Hypertension is a major risk factor for aortic root dilatation in women with Turner's syndrome. Clin Endocrinol (Oxf) 2001;54:69-73.

4. Lin AE, Lippe B, Rosenfeld RG. Further delineation of aortic dilation, dissection, and rupture in patients with Turner syndrome. Pediatrics 1998;102:e12.

5. Gravholt CH, Andersen NH, Conway GS, Dekkers OM, Geffner ME, Klein KO, et al. Clinical practice guidelines for the care of girls and women with Turner syndrome: proceedings from the 2016 Cincinnati International Turner Syndrome Meeting. Eur J Endocrinol 2017;177:G1-70.

6. De Groote K, Devos D, Van Herck K, De Wolf D, Van der Straaten S, Rietzschel E, et al. Increased aortic stiffness in prepubertal girls with Turner syndrome. J Cardiol 2017;69:201-7.

7. Chirinos JA. Arterial stiffness: basic concepts and measurement techniques. J Cardiovasc Transl Res 2012;5: 243-55.

8. Tsuchikura S, Shoji T, Kimoto E, Shinohara K, Hatsuda S, Koyama $\mathrm{H}$, et al. Brachial-ankle pulse wave velocity as an index of central arterial stiffness. J Atheroscler Thromb 2010;17:658-65.

9. Saiki A, Sato $\mathrm{Y}$, Watanabe R, Watanabe $\mathrm{Y}$, Imamura H, Yamaguchi T, et al. The role of a novel arterial stiffness parameter, cardio-ankle vascular index (CAVI), as a surrogate marker for cardiovascular diseases. J Atheroscler Thromb 2016;23:155-68.

10. Takaki A, Ogawa H, Wakeyama T, Iwami T, Kimura M, Hadano $\mathrm{Y}$, et al. Cardio-ankle vascular index is superior to brachial-ankle pulse wave velocity as an index of arterial stiffness. Hypertens Res 2008;31:1347-55.

11. Ibata J, Sasaki H, Kakimoto T, Matsuno S, Nakatani M, Kobayashi M, et al. Cardio-ankle vascular index measures arterial wall stiffness independent of blood pressure. Diabetes Res Clin Pract 2008;80:265-70.

12. Takenaka T, Hoshi H, Kato N, Kobayashi K, Takane H, Shoda J, et al. Cardio-ankle vascular index to screen cardiovascular diseases in patients with end-stage renal 
diseases. J Atheroscler Thromb 2008;15:339-44.

13. Lawson SA, Urbina EM, Gutmark-Little I, Khoury PR, Gao Z, Backeljauw PF. Vasculopathy in the young Turner syndrome population. J Clin Endocrinol Metab 2014;99:E2039-45.

14. Mosteller RD. Simplified calculation of body-surface area. N Engl J Med 1987;317:1098.

15. Matthews DR, Hosker JP, Rudenski AS, Naylor BA, Treacher DF, Turner RC. Homeostasis model assessment: insulin resistance and beta-cell function from fasting plasma glucose and insulin concentrations in man. Diabetologia 1985;28:412-9.

16. Alberti KG, Zimmet P, Shaw J; IDF Epidemiology Task Force Consensus Group. The metabolic syndrome--a new worldwide definition. Lancet 2005;366:1059-62.

17. Expert Panel on Detection, Evaluation, and Treatment of High Blood Cholesterol in Adults. Executive summary of the third report of the National Cholesterol Education Program (NCEP) expert panel on detection, evaluation, and treatment of high blood cholesterol in adults (adult treatment panel III). JAMA 2001;285:2486-97.

18. Hayashi K, Yamamoto T, Takahara A, Shirai K. Clinical assessment of arterial stiffness with cardio-ankle vascular index: theory and applications. J Hypertens 2015;33:174257.
19. Sharma J, Friedman D, Dave-Sharma S, Harbison M. Aortic distensibility and dilation in Turner's syndrome. Cardiol Young 2009;19:568-72.

20. An HS, Baek JS, Kim GB, Lee YA, Song MK, Kwon BS, et al. Impaired vascular function of the aorta in adolescents with Turner syndrome. Pediatr Cardiol 2017;38:20-6.

21. O'Gorman CS, Syme C, Lang J, Bradley TJ, Wells GD, Hamilton JK. An evaluation of early cardiometabolic risk factors in children and adolescents with Turner syndrome. Clin Endocrinol (Oxf) 2013;78:907-13.

22. Wang H, Liu J, Zhao H, Fu X, Shang G, Zhou Y, et al. Arterial stiffness evaluation by cardio-ankle vascular index in hypertension and diabetes mellitus subjects. J Am Soc Hypertens 2013;7:426-31.

23. Payne RA, Wilkinson IB, Webb DJ. Arterial stiffness and hypertension: emerging concepts. Hypertension 2010;55:914.

24. O'Gorman CS, Syme C, Bradley T, Hamilton J, Mahmud FH. Impaired endothelial function in pediatric patients with turner syndrome and healthy controls: a case-control study. Int J Pediatr Endocrinol 2012;2012:5.

25. Lin AE, Lippe BM, Geffner ME, Gomes A, Lois JF, Barton CW, et al. Aortic dilation, dissection, and rupture in patients with Turner syndrome. J Pediatr 1986;109:820-6. 